DOI: 10.31695/IJASRE.2022.8.1.10

\title{
Tourism SMEs usage of Social Media Analytics as their Business Intelligence Tool
}

\author{
Shadrack Stephen Madila ${ }^{* 1,3}$, Dr. Janeth Marwa ${ }^{2}$, Dr. Mussa Ally Dida ${ }^{1}$, Dr. Shubi Kaijage ${ }^{1}$ \\ ${ }^{1}$ School of Computational \& Communication Science and Engineering (CoCSE) \\ Nelson Mandela African Institution of Science and Technology (NM-AIST) \\ ${ }^{2}$ School of Business Studies and Humanity (BuSH), \\ Nelson Mandela African Institution of Science and Technology (NM-AIST) \\ ${ }^{3}$ Department of Information Communication Technology, \\ Moshi Co-operative University (MoCU)
}

Tanzania

\begin{abstract}
This study delivers the results of the survey conducted to investigate the tourism SMEs' usage of social media analytics as their business intelligence tool. The study uses the unified theory of acceptance and use of technology (UTAUT) model to investigate the usage of SMA to tourism SMEs. 71 tourism SMEs were interviewed in Arusha and Kilimanjaro regions by filling the semistructured questionnaires, then followed by the data analysis using MS excel and Python. The results of the findings show that the usage of social media analytics as a business intelligence tool for tourism SMEs is beneficial to them, however, findings show very few tourism SMEs are conducting social media analytics on their social media platforms. Most tourism SMEs use built-in social media analytics and they are performing simple metrics like counting the number of likes, comments, and shares. Further results explain that the majority of the tourism SMEs don't have more information and knowledge about social media analytics and tools used to perform social media analytics as well as they are performing social media analytics without following any implementation framework to guide the process. The study recommends that social media stakeholders increase awareness of social media analytics to tourism SMEs so that they could use it and get more advantages of using social media. Furthermore, researchers information systems analysts and developers develop social media analytics tools specifically for tourism SMEs and provide them step-by-step procedures that will help them in using and managing the social media analytics activities.
\end{abstract}

Keywords: Social Media, Social Media Analytics, Tourism SMEs, Business Intelligence.

\section{INTRODUCTION}

Ananthan et al. (2018), defines social media as "a website that facilitates meeting people, finding like minds, communicating and sharing content and building community, this kind of website allows or encourages various types of activities such as commercial, social or combination of the two". Initially, social media was used for communication between peers sharing of content and minimizing the physical distance, currently, it is an important instrument for enhancing contact among customer to customer, customer to company and business to business by making improvements on information flows as well as relationships [1]. Some commonly used social media platforms include Facebook, Instagram, google+, Twitter, Youtube and others.

Social media changed the way SMEs and organizations are doing business nowadays, it creates many business opportunities for social media users' organizations. Social media platforms are free tools which can be used by small organizations and big organizations for promotions of their products, customer relations management and other business services [2].

Using social media in business processes activities causes an increase in data as contents, comments and messages on social media platforms. For SMEs to get full advantages of using social media it has to process these vast amounts of data to get insight from it. Social media analytics (SMA) is defined as a combination of data mining techniques, tools and analytics methods to collect data, monitor them and analyse these massive social media data to get useful patterns, providing insight and enhancing business 
intelligence [3]. SMA exploits various approaches like performing sentiment analysis, conducting insight mining, trend analysis, prediction analysis, conducting trend analysis, network analysis and even visual analytics to listen to the user-generated contents from the social media platforms [4].

According to (Ruhi,2014) business intelligence includes techniques that firms use to obtain, analyse and disseminate information to be used for business decision making. Customer insights obtained through business intelligence are also used as input for improving product and service innovation [5]. Social media intelligence and forecasting are directly applied to various business intelligence problems i.e., understanding the spreads of information and performing sentiment of the messages which have been spread can provide analyst insight into the purse of the organization brand and products [6].

Tourism SMEs are those small business firms that operate in the tourism sector, these firms include hotels, tour guide operating companies, travel agents, bar and restaurants and airline operators. Tourism SMEs are using social media business external networking, business internal networking and for competitive advantages in business [7]. In developing countries, the status of SMA usage for tourism SMEs is quietly known much as many of the studies in social media analytics in tourism sector are from developed countries. Mirzaalian and Halpenny (2019) explain that majority of the SMA studies in tourism are from developed countries in Asia, Europe, North and south America and Oceania where many studies are from USA and China.

The study's objectives were to investigate the current status of tourism SMEs usage of social media analytics tools as their tool for conducting business intelligence and finding the key areas where the tourism SMEs are used to find insight about from social media to make decisions in their business operations.

\section{LITERATURE REVIEW}

\subsection{Social Media Analytics}

SMA is the field of study which performs analysis of contents from the social media platforms which are structured and unstructured. SMA develops and evaluates tools and frameworks for collecting, monitoring, analysing social media data and providing visualization of social media data [8]. SMA uses different techniques in analyzing structured and unstructured data from social media platforms, some of the methods and techniques used include text mining, social network analysis, trend analysis and sentiment analysis [9].

For business firms to make decisions there is increasing consideration of the use of social media data as they are timely available information. Other business firms use social media data to improve and upgrade their products. The use of social media analytics helps firms to gather new ideas, suggestions and good solutions from the customers' comments and posts on their social media platforms which will help to attain their competitive advantages [10]. Ndiege (2018) argued that for SMEs to exploit full advantages of using social media platforms they must utilize SMA tools in their social media usage.

\subsection{Social Media Analytics in Tourism}

SMA is performed in several tourism and hospitality organizations including hotels, tour guide operators' restaurants and others to help them to make decisions in different business aspects as well as to measure their social media campaigns. Mirzaalian and Halpenny (2019) identified the common SMA approaches performed by tourism SMEs as text analysis and sentiment analysis, contents analysis, topic modelling, trend analysis, predictive analysis, social network analysis, spatial analysis and comparative analysis. Several studies explain the usage of social media analytics in the tourism and hospitality field. Chang et al. (2017) conducted a study on SMA in hotels and accommodation firms. The study proposed the framework for implementing sentiment analysis on the customers' reviews posted on trip advisors. Xiang et al. (2016) explain how social media analytics can be used to find market intelligence for hotels. The study performed sentiment analysis to find insight on the market intelligence using Twitter social media data.

Another study conducted by Park et al. (2016) introduces the usage of SMA in examining the emotions of restaurant customers in Asia, using sentiment analysis on the Twitter social media platform. He et al. (2017) conducted a study in performing the reviews of customer comments from different hotels using sentiment analysis to the comments in trip advisor. Berezina et al. (2015) uses sentiment analysis to identify satisfied customers and dissatisfied customers of the hotel using hotel reviews from the social media platforms, and identify the areas where they are satisfied or not satisfied. 
International Journal of Advances in Scientific Research and Engineering (ijasre), Vol 8 (1), January -2022

\section{RESEARCH BACKGROUND FRAMEWORK}

For investigating the SMA usage to tourism SME's the study uses the social psychological theory which explain the acceptance and usage of information technology services and tools. Venkatesh, Davis, Morris and Davis (2003) introduced a unified theory of acceptance and use of technology (UTAUT). Venkatesh et al. (2003) explains that the acceptance and use of ICT technology rely on four variables, perceived usefulness, perceived ease of use, social influence and facilitating conditions. Perceived usefulness as explained by Davis (1989) is the perception of users on the technology that using such technology will improve the productivity of the organization, Davis (1989) defined perceived ease of use as "the degree to which a person believes that using a particular system would be free of effort". These two variables form a technology acceptance model (TAM). Other two variables were added to UTAUT which are social influence and facilitating conditions. Social influence as it was explained by Venkatesh et al. (2003) is the condition in which a person perceives that important other people believe that she or he should use the technology or system. Facilitating condition is "the degree to which an individual believes that an organizational and technical infrastructure exists to support use of the system" [11].

The study determined how tourism SMEs use SMA in their business process and in what areas they use SMA to find insight in their social media pages. Using UTAUT model basic components the questionnaire was developed to answer the research questions.

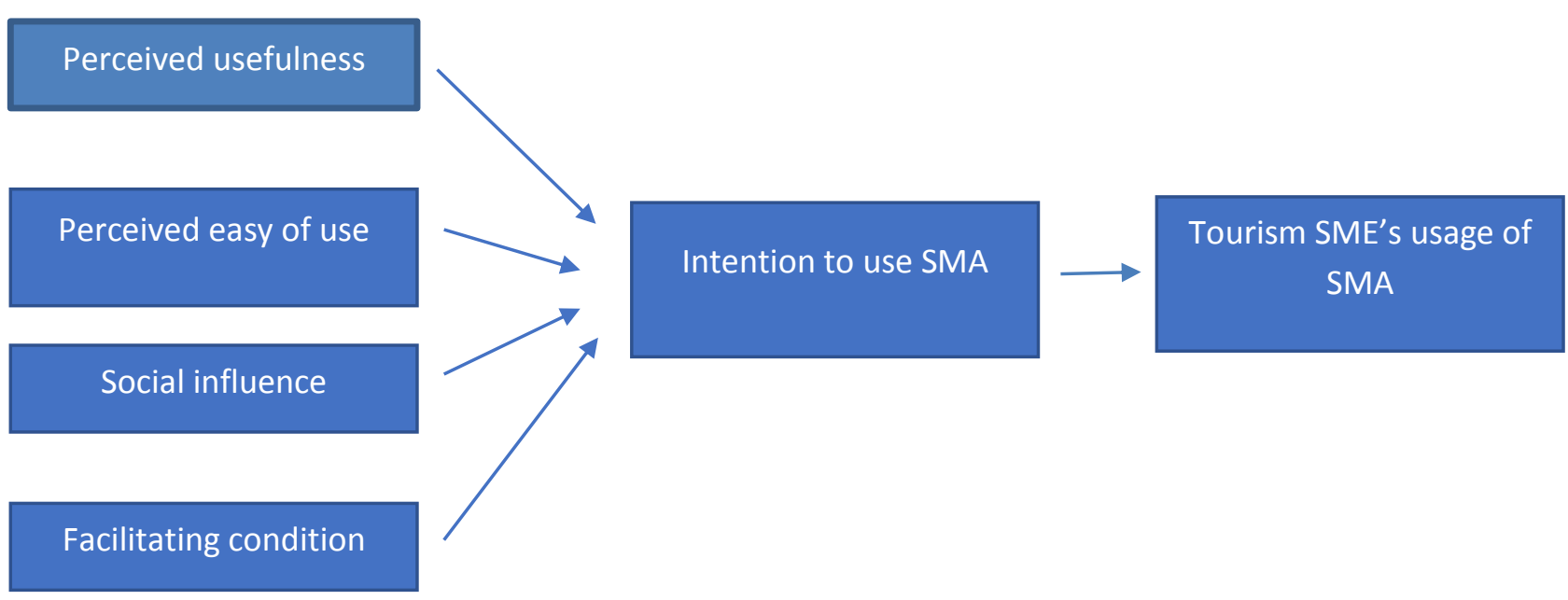

Figure 1. Research framework

\section{METHODOLOGY}

The study collected qualitative and quantitative data by surveying tourism SMEs in Arusha and Kilimanjaro region. Arusha and Kilimanjaro regions are within the northern circuit of the Tanzania tourism zone with a rich of Tourism SMEs Many tourism SMEs have their head office in these regions, hence it was easy for the researcher to meet the expected respondents. Kilangi (2012) approved that it is hard to establish a complete population for tourism SMEs in Tanzania, the study found 92 tourism SMEs in Arusha region and 60 tourism SMEs in the Kilimanjaro region. In our study, these 152 tourism SMEs have been taken as the tourism SMEs population in Arusha and Kilimanjaro regions. 71 tourism SMEs respondents were interviewed 35 from Arusha and 36 from Kilimanjaro. The distribution of the tourism SMEs were 21 hotels and restaurants, 26 travel agents, 23 tour operators and 1 air operator. Purpose sampling was used to select the tourism SMEs, hence both interviewed tourism SMEs are those which are using social media platforms in their business activities. 


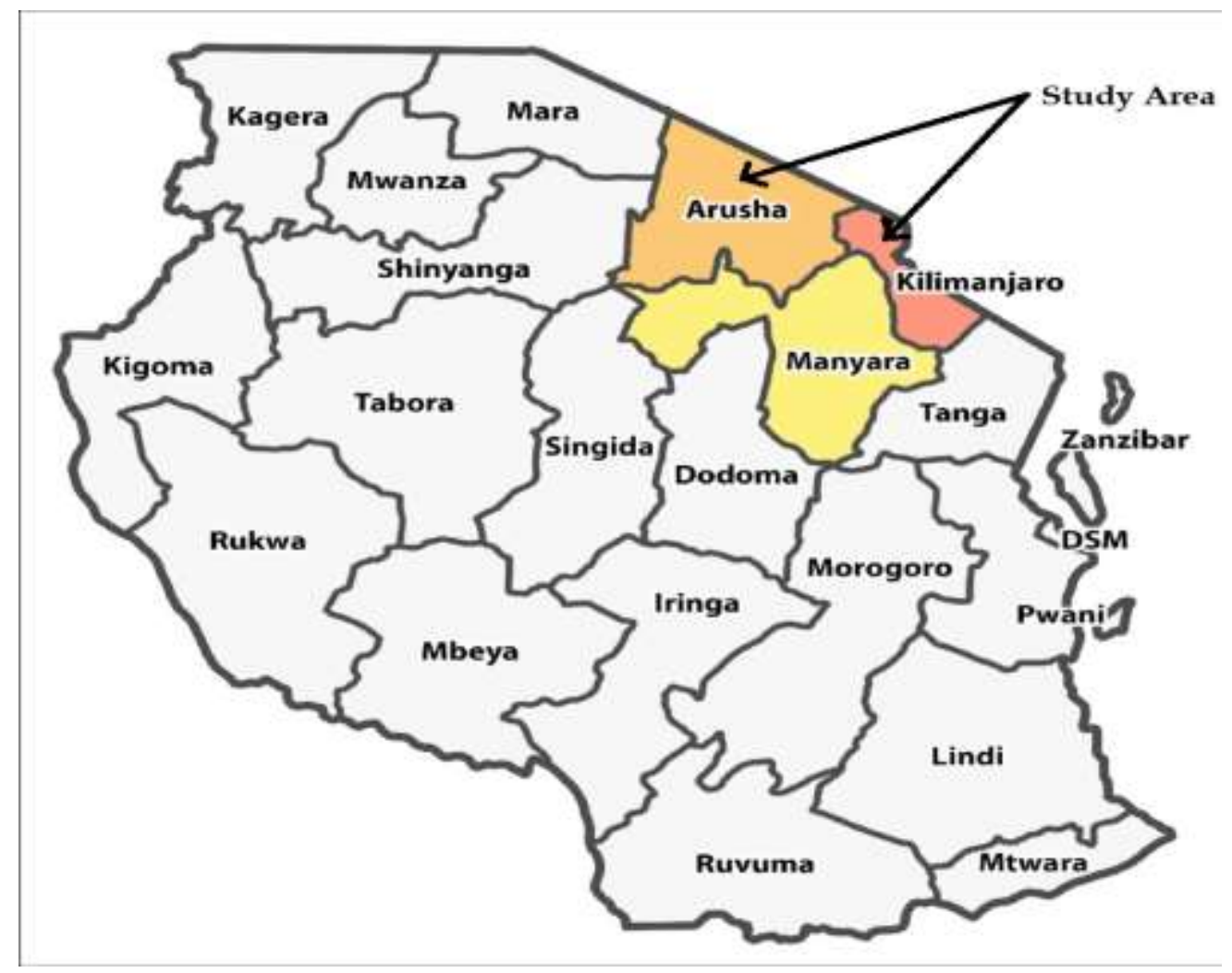

Figure 2. The research study area

Questionnaires were developed based on the research goals, objectives and the reviewed literature. The study adhered to ethical issues such as respondents' consent and data privacy. It took two months for data collection; the questionnaires were distributed through google forms and printed copies to tourism SMEs respondents. Collected data were analyzed using descriptive statistics techniques. Data was coded in Microsoft Excel and analyzed in Microsoft Excel and python. Descriptive statistics like frequency and percentages were produced based on these data analysis tools.

\section{RESULTS OF ANALYSIS}

\subsection{Tourism SMEs and respondent's information}

The respondent's and tourism SMEs information were gathered in the first five questions. The study desired to understand the types of the tourism organization, the organization head office, nature of the organization, respondent's position in the organization and the respondent's education level. The tourism SMEs were hotels/restaurants 21, travel agents 26, tour guide operator 23 and one (1) air operator. 35 tourism SMEs have their head office in Arusha and 36 tourism SMEs are from Kilimanjaro. The nature of the organization was 1 for the local market, 3 tourism SMEs for the regional market and 67 tourism SMEs for the international market. 18 interviewed tourism SMEs working as operational managers, 5 respondents were owners of the tourism SMEs, 1 respondent was reservation manager, 1 respondent was general manager, 15 were managing directors, 25 respondents were sales and marketing managers, 3 respondents were IT managers and 3 financial managers. Respondent's education profile was 3 master's degrees, 61 respondents they have a bachelor degree, 1 respondent certificate in tourism, 3 respondents they have advanced secondary school certificate and other 3 respondent's they have ordinary secondary school certificate.

\subsection{Tourism SMEs social media platforms}

Tourism SMEs surveyed have a presence in more than one social media platforms. The main social media platforms used by these tourism SMEs were Linkedin, google+, Twitter, Instagram and Facebook. In our survey we found that Facebook is used much more than any other social media platform, 69 SMEs are using Facebook which is $97.18 \%$ of all tourism SMEs surveyed, another most used social media platform is Instagram, 63 tourism SMEs which is $88.73 \%$. Followed by Twitter 28 SMEs equals $39.43 \%$, google+ 15 SMEs which is $21.12 \%$ and Linkedin 8 SMEs equal to $11.26 \%$ 


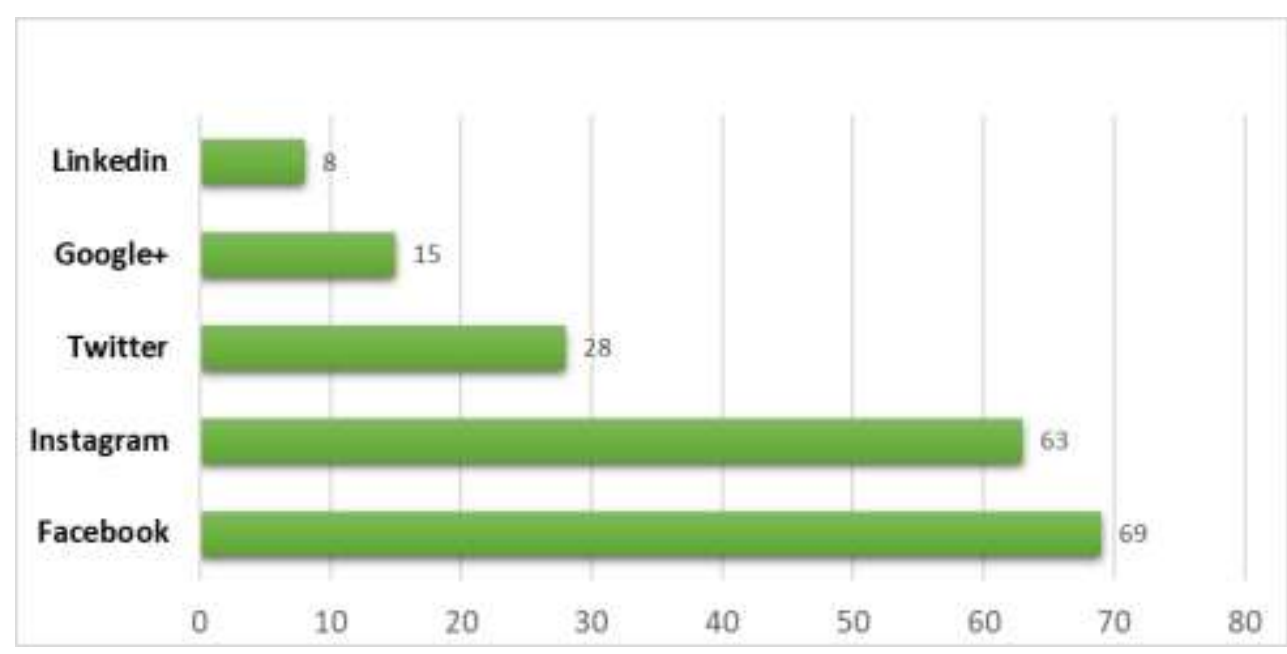

Figure 3. Tourism SMEs social media platforms

\subsection{The purpose for Tourism SMEs is to use social media}

Tourism SMEs are using social media for various purposes in their business activities. Depending on their business activities, tourism SMEs have more than one purpose for using social media. The survey results show that of 66 tourism SMEs $92.96 \%$ of their purpose of using social media is advertising and promotions. 57 tourism SMEs $80.28 \%$ are using social media for reaching new customers, another 50 tourism SMEs $70.42 \%$ their purpose of using social media is managing customer relationships. 43 tourism SMEs $60.56 \%$ said that they use social media for receiving customer feedback and the other 22 tourism SMEs which is $30.98 \%$ mentioned that they use social media for brand awareness. 19 SMEs equals $26.76 \%$ they mentioned that their use of social media is just to get likes, shares and followers in social media.

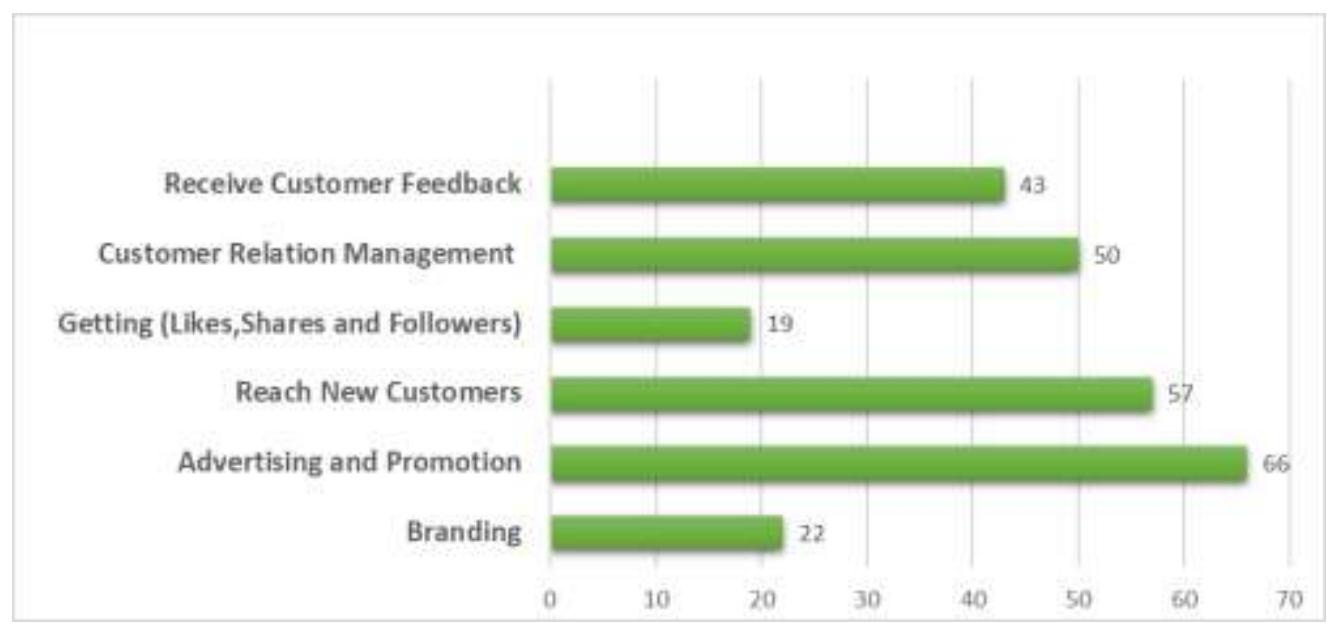

Figure 4. Tourism SMEs purpose of using social media

\subsection{Tourism SMEs influence to use social media}

The study wants to examine the factors which influence tourism SMEs to adopt and use social media in their business process. The response for this question is as follows, 33 SME's equals to $46.48 \%$ their influence in using social media in business is because they want to use technology over their business activities, 26 SME's equal to $36.62 \%$ they get motivated to use social media their customers are using social media and the remaining 12 SME's $16.90 \%$ they are influenced by other companies who are using social media in their business activities. 


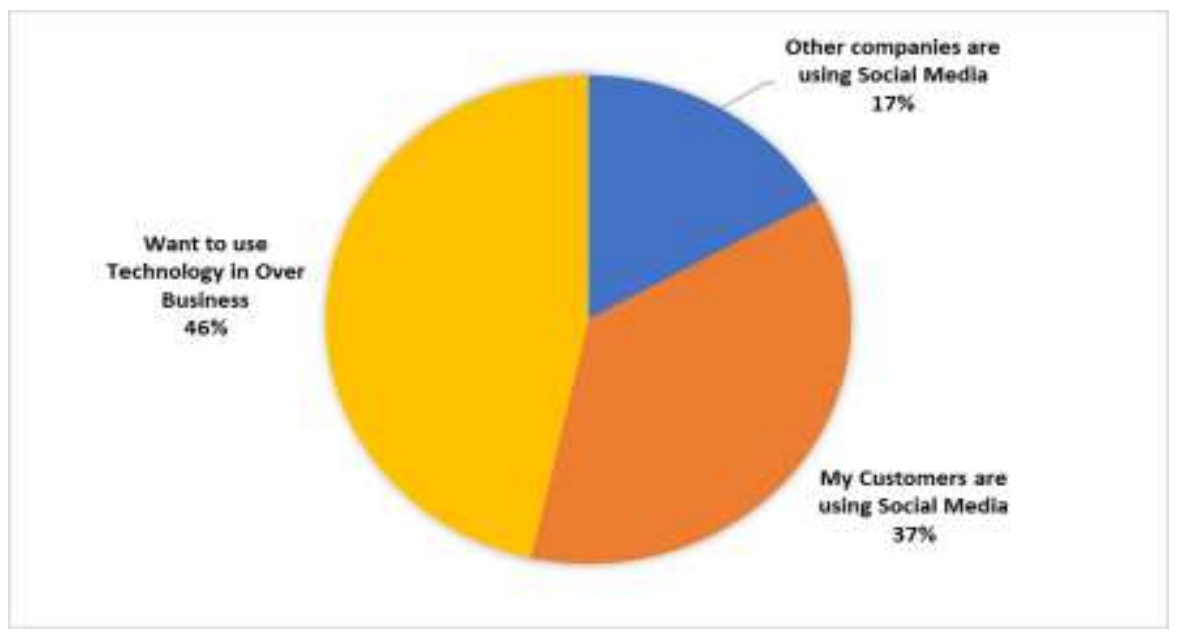

Figure 5. Tourism SMEs influence to use social media

\subsection{Tourism SMEs social media analytics information and knowledge}

The surveyed tourism SMEs' knowledge and information about SMA were identified during the survey. The aim was to check if these tourism respondent's and managers know with social media analytics tools and technology. $19.71 \%$ of the surveyed tourism SMEs respondents agreed that they have information about SMA. 2.28\% of the tourism SMEs respondents responded that they have good information about SMA, another 2.28\% of the tourism SMEs respondents agreed that they have excellent information about SMA. $42.25 \%$ of the tourism SMEs mentioned that they have no information and no knowledge about SMA and the remained 32.39 tourism SMEs respondents mentioned to have little information and knowledge about SMA. These results show that the majority of the tourism SMEs respondents and managers don't have enough information and knowledge about the usage of the SMA. Some of the managers replied that they didn't even know that data from the social media platforms can be retrieved and converted into meaningful information for their business intelligence.

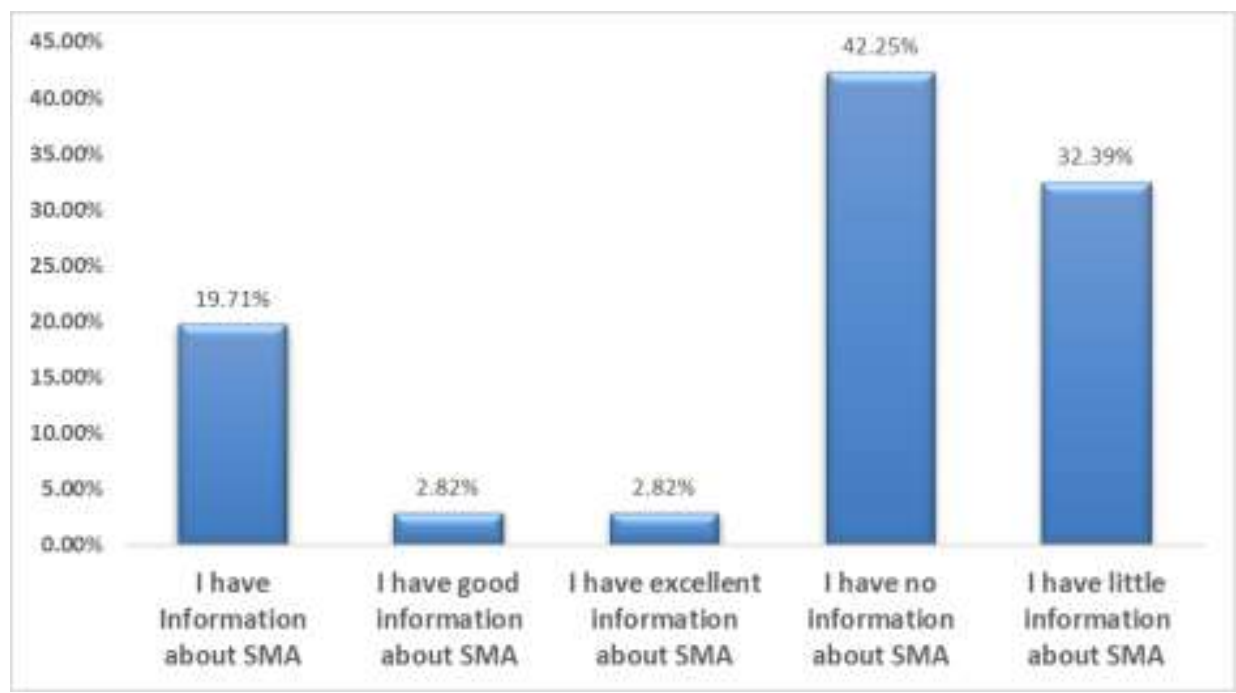

Figure 6. Tourism SMEs respondent's knowledge and information of SMA

\subsection{Tourism SMEs usage of social media analytics tools}

The study found that the majority of the tourism SMEs surveyed are not doing social media analytics in their social media business activities using any social media analytics tool. Hence these SMEs are not getting any insight from the social media data available on their social media platforms. The results show that only 19 tourism SMEs equals $27 \%$ of the surveyed tourism SMEs are conducting SMA in their social media data while the remaining 52 tourism SMEs which is $73 \%$, are not performing SMA in 
their social media platforms and campaigns. One of the hotel respondents mentioned that "I didn't know that there are tools which can be used to gather social media data and get insight from it, I just post in my social media platforms and customers comments on the pages"

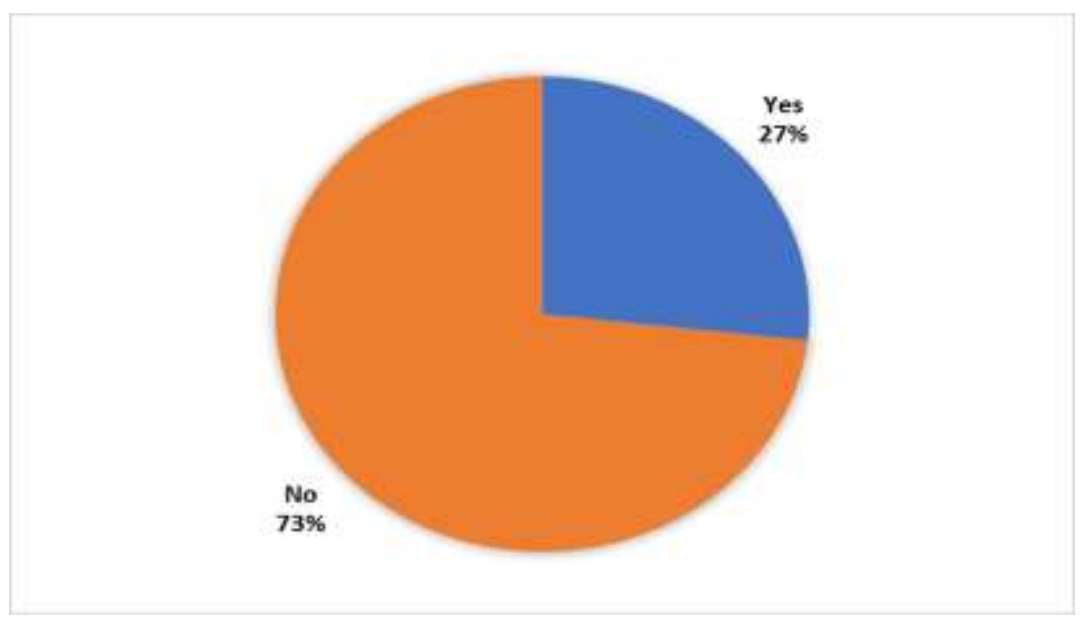

Figure 7. Tourism SMEs usage of SMA

\subsection{Tools used by tourism SMEs in Social media analytics}

19 tourism SMEs who performed social media analytics have been required to mention some of the SMA tools they are using in getting insight from the social platforms. The majority of the tourism SMEs are using built-in social media analytics tools e.g., Facebook analyser, Twitter analyser and Instagram insight, these comprise of 15 tourism SMEs equals to $78.95 \%$ other tools used are 1 tourism SME which $5.26 \%$ is using followerwonk, 1 tourism SME is using cyte, 1 tourism SME is google analytics and the other one tourism SME is using Buzzsumo.

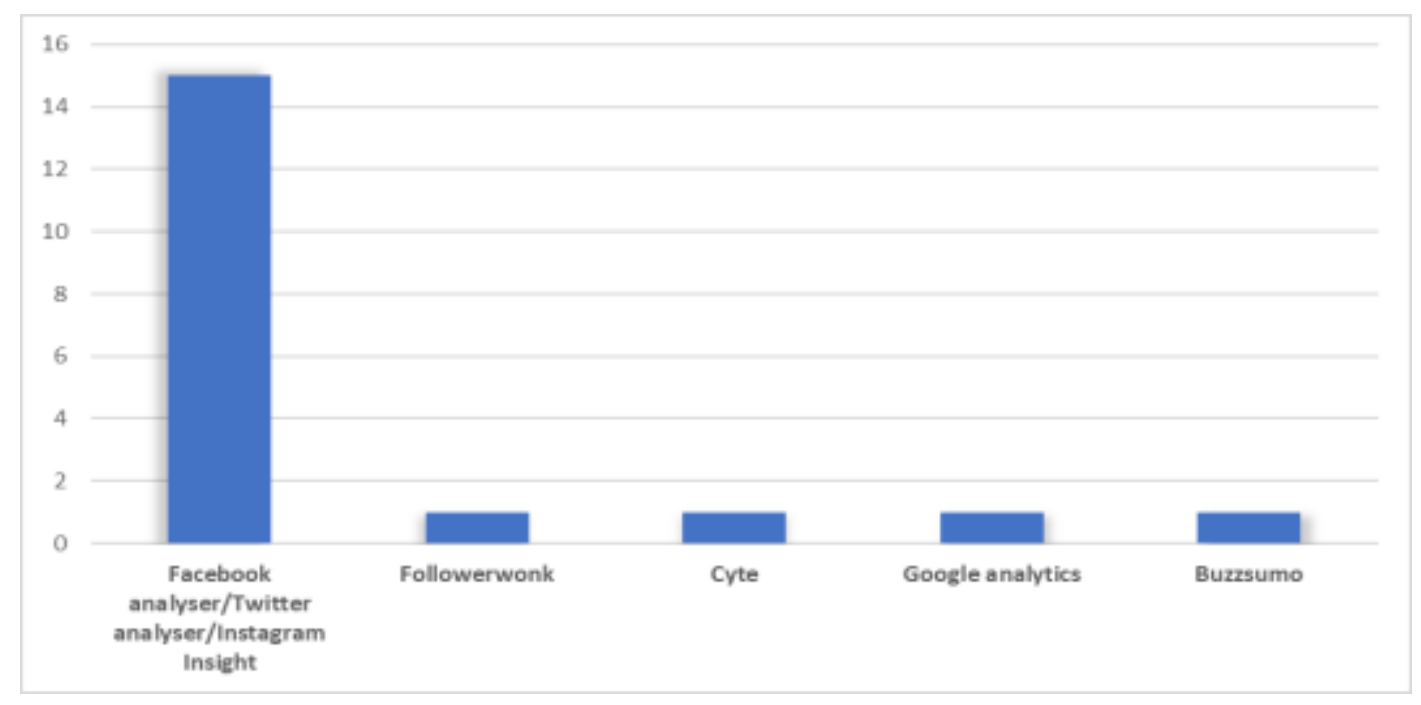

Figure 8. SMA tools used by tourism SMEs

\subsection{Social media metrics measured by tourism SMEs during SMA}

Tourism SMEs use different metrics in measuring the activities in social media analytics. Tourism SMEs are performing several measurements in social media analytics. The surveyed results categorize the metrics used to measure tourism SMEs social media analytics as follows, 19 tourism SMEs who perform SMA mentioned that they used to count the number of followers in social media platforms. This is followed by 16 tourism SMEs who mentioned that during SMA they used to measure the received number of likes and comments on the tourism SMEs social media platforms.14 tourism SMEs mentioned that they used to count the number of visitors to their social media platforms, 5 tourism SMEs said that they used to count bookings from social media 
platforms. 3 tourism SMEs mentioned that they use to see trending topics in social media, 2 tourism SMEs used to count the number of clicks and responses to the social media platform as well as other 2 tourism SMEs are used to perform sentiment analysis in SMA. These results indicate that majority of the tourism SMEs are used to perform low-level SMA metrics instead of the advanced SMA metrics like predictions and sentiments analysis. One respondent replied that "I just counting the number of likes and comments so that I can measure the popularity of the post in my social media pages"

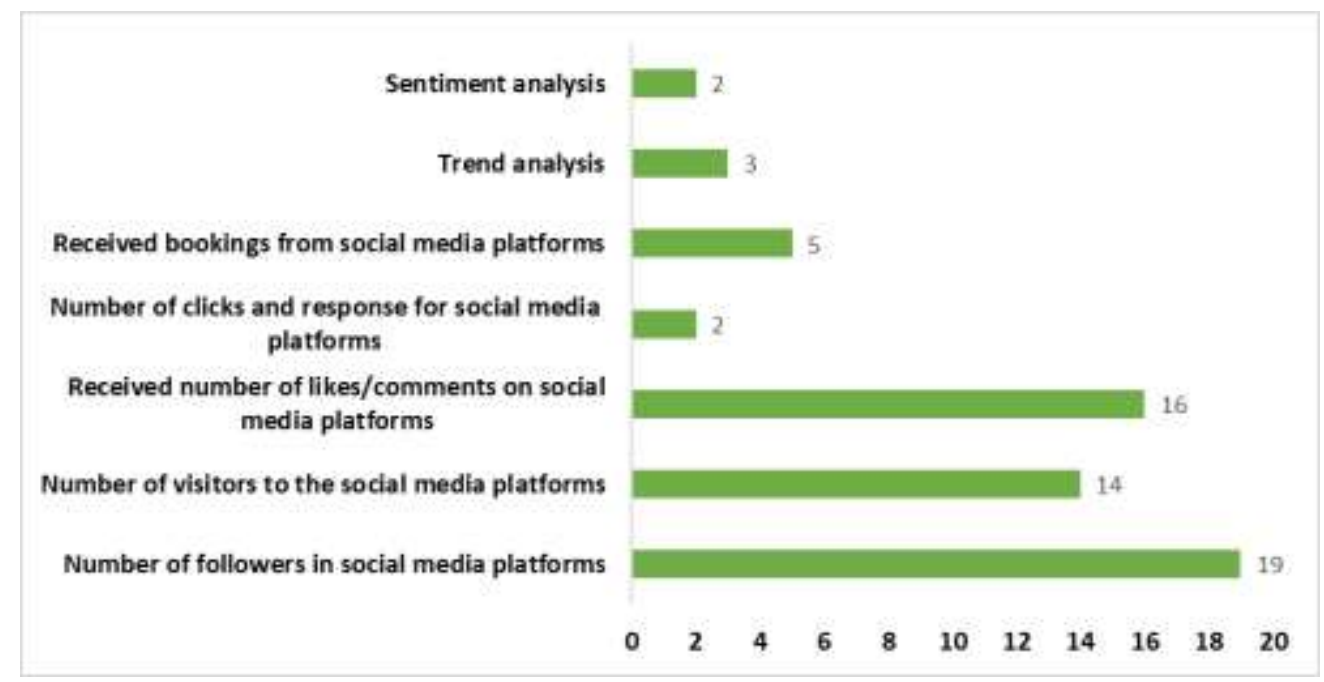

Figure 9. Social media metrics measured by tourism SMEs

\subsection{Tourism SMEs expert in performing SMA}

The study wants to know the expert who performs the SMA to tourism SMEs social media platforms. The surveyed results from 19 tourism SMEs who perform SMA shows that $68 \%$ of the tourism SMEs are using an expert within the organization to perform SMA. This followed by $21 \%$ of the tourism SMEs who use experts from outside the organization to perform SMA and the remaining $11 \%$ of the tourism SMEs mentioned that they use experts from within the organization and outside the organization to perform SMA.

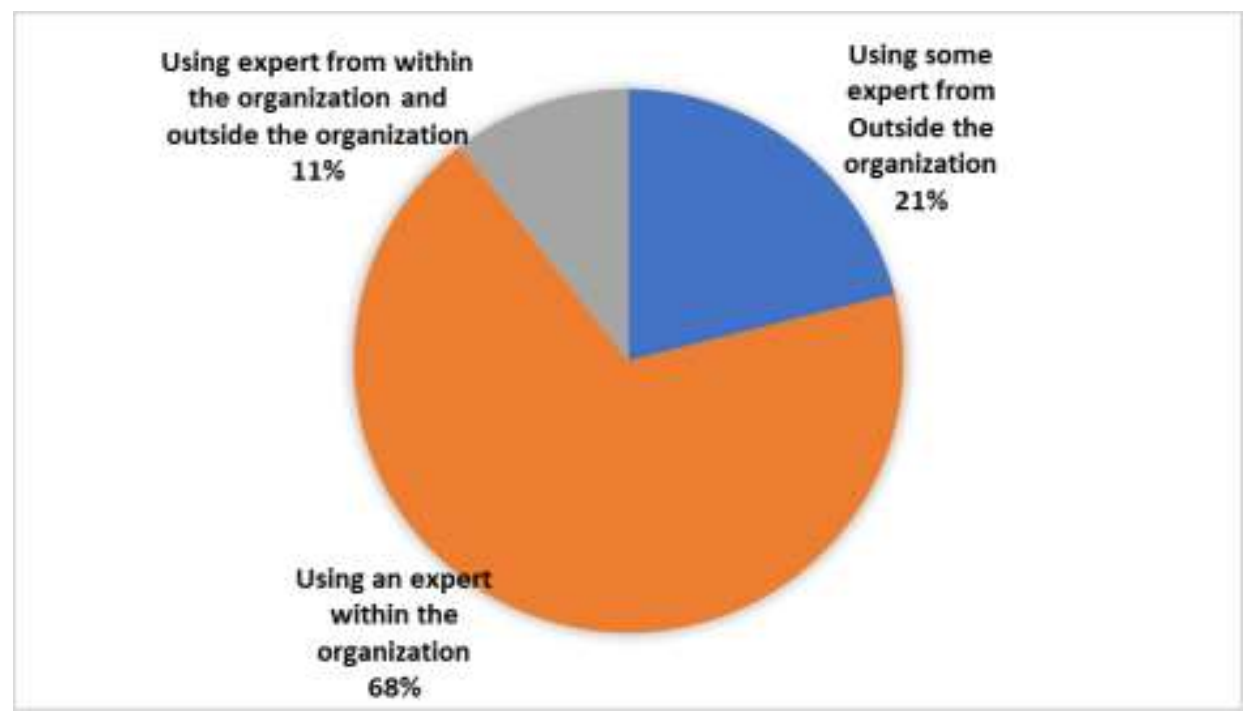

Figure 10. Tourism SMEs expert to perform SMA

\subsection{The benefit observed to tourism SMEs in doing SMA}

The respondents from tourism SMEs who conduct SMA were asked to state the benefit is counted from performing the SMA to their social media platforms. The majority of the tourism SMEs, 15 equals $79 \%$ respondents agreed that the SMA tools are extremely beneficial. 1 tourism SME which is $5 \%$ states that SME is not getting any benefit by conducting SMA. Another 1 
tourism SME which is 5\% mentioned that SMA has little benefit to tourism SMEs and the other 2 tourism SMEs equals $11 \%$ agreed that conducting SMA has somewhat benefit to tourism SMEs social media activities.

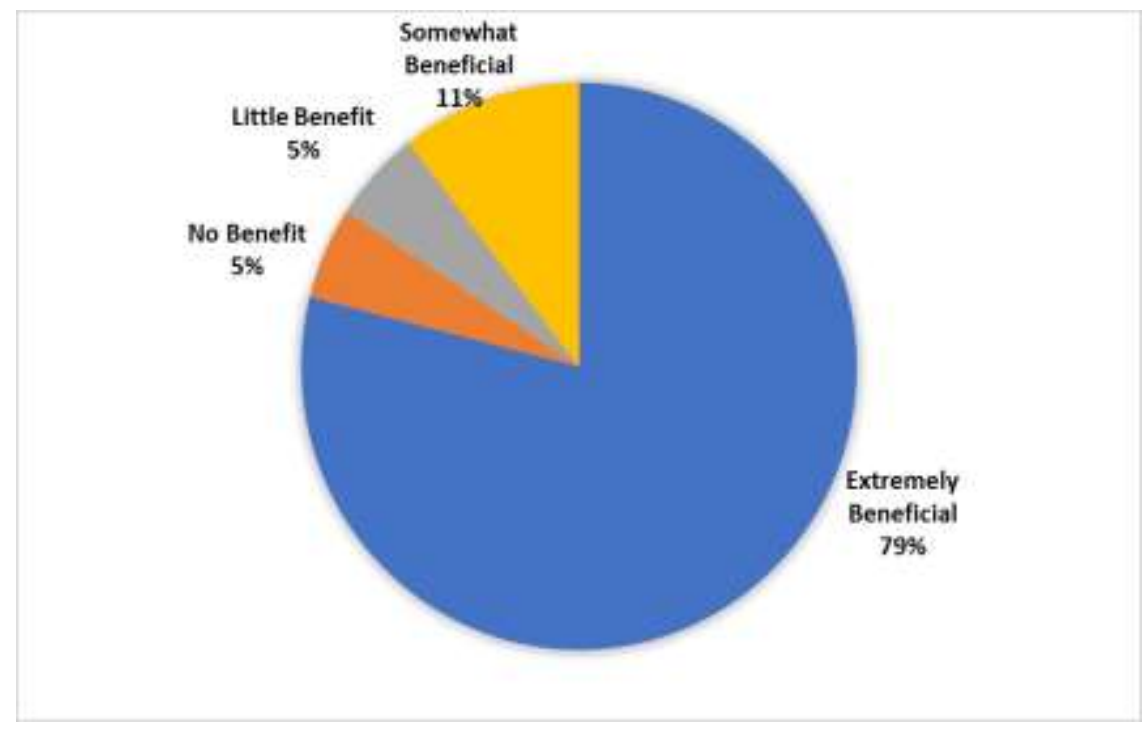

Figure 11. Tourism SMEs benefit from doing SMA

\subsection{Procedure's tourism SMEs used to conduct SMA}

The tourism SMEs were asked if there are any procedures of the SMA implementation framework they are following in conducting and managing SMA activities in their social media platforms. Out of 19 tourism SMEs who conduct SMA, 5 tourism SMEs 26\% mentioned that they are following their step-by-step procedures in conducting SMA. The remaining 14 tourism SMEs equals $74 \%$ state that they are not following any procedures of implementation framework in conducting and managing their SMA activities. These results show that the majority of the tourism SMEs are doing SMA using their own procedures without following any common step by step guidelines for conducting and managing SMA activities.

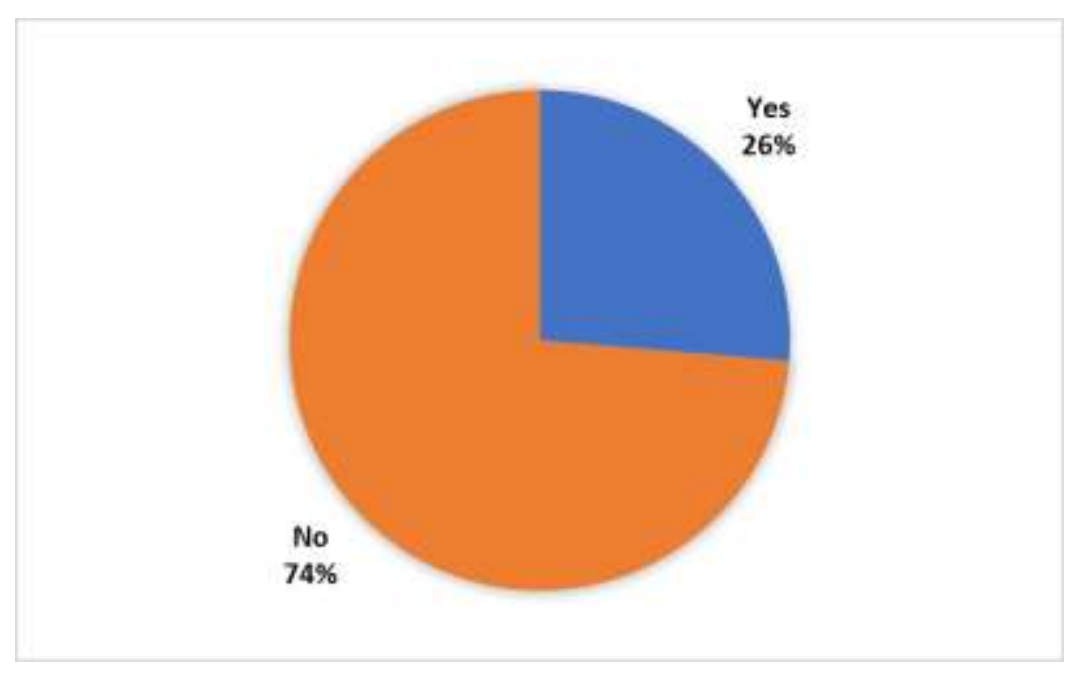

Figure 12. Tourism SMEs procedures of doing SMA

\subsection{Area's tourism SMEs used to find insight about in Business activities}

Tourism SMEs responded to the question regarding what are the business areas they used to find insight about from the customers and the community using their social media platforms. Tourism SMEs can find insight from social media in more than one area of business activities. Figure.10 below shows the respondents results from the 19 tourism SMEs who perform SMA. Majority of the tourism SMEs 16 which is $84.21 \%$ mentioned that they find insight about marketing and promotions, 14 tourism SMEs $73.68 \%$ said that they find insight about brand awareness, 14 tourism SMEs which is $73.68 \%$ mentioned that they are finding insight about customer relationship and other 6 tourism SMEs equals to $31.57 \%$ mentioned that they find insight about customer feedback. 


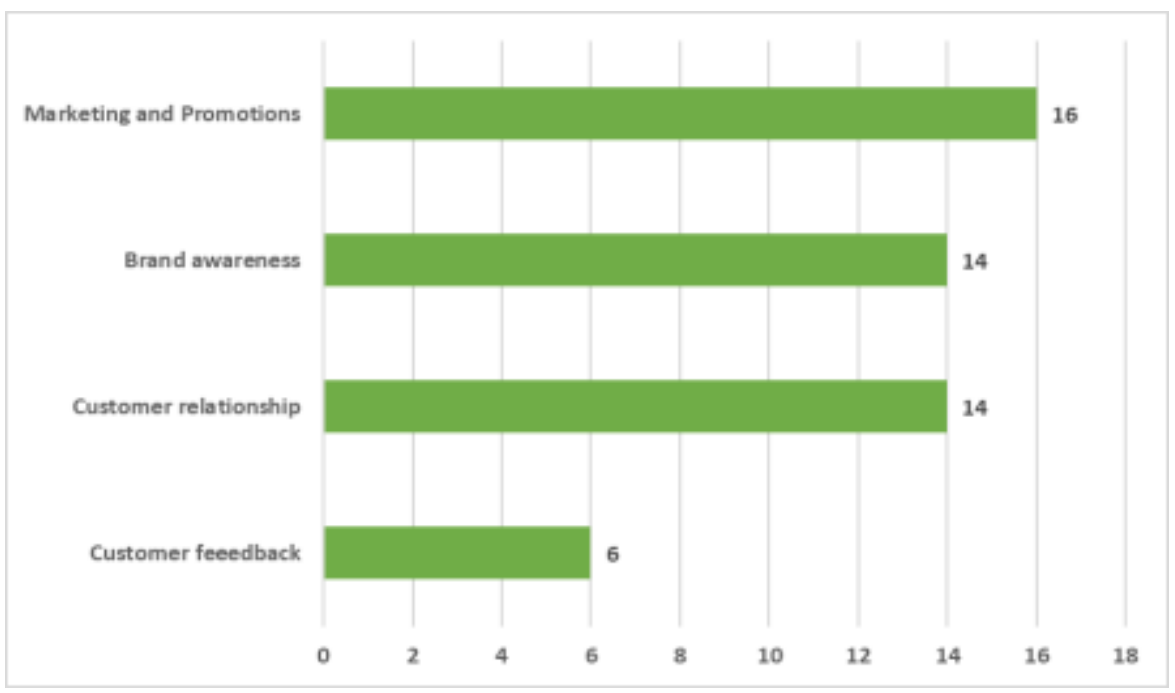

Figure 13. Area Tourism SMEs used to find insight about

\section{CONCLUSION}

The study purposes were to investigate the usage of SMA to tourism SMEs as a business intelligence tool in Tanzania. 71 tourism SMEs were surveyed and survey data has been collected and analyzed. Data presented shows that SMA is an essential technology for the future of tourism SMEs. The surveyed results show that the majority of the tourism SMEs are not performing SMA in their social media business activities, and many of the tourism SMEs respondents and managers don't have enough knowledge and information about SMA technologies and tools. The study found that $27 \%$ of the surveyed tourism SMEs are performing SMA where the majority of them are using built-in social media analytics tools from the social media platforms e.g., Facebook analytics, Twitter analyser and Instagram insight. These few tourism SMEs who are performing SMA use simple metrics like counting the number of likes and comments, the number of visitors and counting number of shares. Results also show that common areas where tourism SMEs used to find insight are marketing and promotions, brand awareness, customer feedback and customer relationship. The majority of the surveyed tourism SMEs about 74\% they don't have a common procedure to manage and guide the usage of SMA.

The study has several contributions specifically to provides the current status of the usage of SMA to tourism SMEs in Tanzania, specify the areas which tourism SMEs finds insight in social media data as well as reveals that tourism SMEs performs SMA without any known implementation framework.

The study made a general conclusion that the usage of SMA to tourism SMEs has positive benefits even though very few tourism SMEs are performing SMA to their social media business activities. The study recommends that researchers, social media influencers and other stakeholders increase knowledge and information to tourism SMEs on the usage of SMA and provide a step by step guiding framework for the usage of social media analytics tools. This will increase the number of users and will provide tourism SMEs full advantages of using social media in their business activities.

\section{ACKNOWLEDGEMENT}

The authors acknowledge the Tanzania Ministry of education technology and vocational studies for funding and supporting this study through MoEST scholarship.

\section{REFERENCES}

1. J. Prodanova and A. Van Looy, "How Beneficial is Social Media for Business Process Management? A Systematic Literature Review," in IEEE Access, vol. 7, pp. 39583-39599, 2019, doi: 10.1109/ACCESS.2019.2903983.

2. Dlamini, N.N. and Johnston, K. (2018), "The use of social media by South African organisations", Journal of Advances in Management Research, Vol. 15 No. 2, pp. 198-210. https://doi.org/10.1108/JAMR-05-2017-0063 evidence from Kenya.

3. He, W., Shen, J., Tian, X., Li, Y., Akula, V., Yan, G. and Tao, R. (2015), "Gaining competitive intelligence from social media data: Evidence from two largest retail chains in the world", Industrial Management \& Data Systems, Vol. 115 No. 9, pp. 1622-1636. 
4. Holsapple, Clyde, Hsiao, Shih-Hui, \& Pakath, Ram. (2014). Business Social Media Analytics: Definition, Benefits, and Challenges. Paper presented at the 20th Americas Conference on Information Systems, Savannah, Georgia, USA

5. Barbara Dinter and Anja Lorenz (2012). "Social Business Intelligence: a Literature Review and Research Agenda". In: Thirty Third International Conference on Information Systems (ICIS 2012). Ed. by F. George Joey. Orlando, Florida: Association for Information Systems. isbn: 978- 0-615-71843-9. url: http://aisel.aisnet.org/icis2012/proceedings/ResearchInProgress/104/

6. Lu, Yafeng \& Wang, Feng \& Maciejewski, Ross. (2014). Business Intelligence from Social Media: A Study from the VAST Box Office Challenge. Computer Graphics and Applications, IEEE. 34. 58-69. 10.1109/MCG.2014.61

7. Mosweunyane, L., Rambe, P. \& Dzansi, D., 2019, 'Use of social media in Free State tourism small, medium and micro enterprises to widen business networks for competitiveness', South African Journal of Economic and Management Sciences 22(1), a2780. https://doi.org/ 10.4102/sajems.v22i1.2780

8. Mirzaalian, F. and Halpenny, E. (2019), "Social media analytics in hospitality and tourism: A systematic literature review and future trends", Journal of Hospitality and Tourism Technology, Vol. 10 No. 4 , pp. 764790. https://doi.org/10.1108/JHTT-08-2018-0078

9. Workneh Yilma Ayele and Gustaf Juell-Skielse. 2017. Social media analytics and internet of things: survey. In Proceedings of the 1st International Conference on Internet of Things and Machine Learning (IML '17). Association for Computing Machinery, New York, NY, USA, Article 53, 1-11. DOI:https://doi.org/10.1145/3109761.3158379

10. He, W., Tian, X., Tao, R., Zhang, W., Yan, G. and Akula, V. (2017), "Application of social media analytics: a case of analyzing online hotel reviews", Online Information Review, Vol. 41 No. 7, pp. 921-935. https://doi.org/10.1108/OIR-072016-0201

11. Anandhan, L. Shuib, M. A. Ismail and G. Mujtaba, "Social Media Recommender Systems: Review and Open Research Issues," in IEEE Access, vol. 6, pp. 15608-15628, 2018, doi: 10.1109/ACCESS.2018.2810062

12. Venkatesh, V., Morris, M. G., Davis, G. B. \& Davis, F. D. (2003). User acceptance of information technology: toward a unified view. MIS Quarterly, 27 (3), 425-478

13. Barbara Dinter and Anja Lorenz (2012). "Social Business Intelligence: a Literature Review and Research Agenda". In: Thirty Third International Conference on Information Systems (ICIS 2012). Ed. by F. George Joey. Orlando, Florida: Association for Information Systems. isbn: 978- 0-615-71843-9. url: http://aisel.aisnet.org/icis2012/proceedings/ResearchInProgress/104/

14. Berezina K., Bilgihan A., Cobanoglu C., and Okumus F., (2015): Understanding Satisfied and Dissatisfied Hotel Customers: Text Mining of Online Hotel Reviews, Journal of Hospitality Marketing \& Management, DOI: 10.1080/19368623.2015.983631

15. Chang, Y.-C., Ku, C.-H. and Chen, C.-H. (2017). Social media analytics: Extracting and visualizing Hilton hotel ratings and reviews from TripAdvisor. International Journal of Information Management, 48, $263-279$. https://doi.org/10.1016/j.ijinfomgt.2017.11.001

16. Davis, F. D. (1989). Perceived usefulness, perceived ease of use, and user acceptance of information 37 technology. MIS Quarterly, (September), 319-340

17. Ndiege,J.R.A (2019) "Social media technology for the strategic positioning of small and medium-sized enterprises: Empirical evidence from Kenya," Electron. J. Inf. Syst. Dev. Ctries., vol. 85, no. 2, pp. 1-12, 2019. https://doi.org/10.1002/isd2.12069.

18. Park, S. B., Jang, J. and Ok, C. M. (2016). Analyzing Twitter to explore perceptions of Asian restaurants. Journal of Hospitality and Tourism Technology, 7(4), 405-422. https://doi.org/10.1108/JHTT-08-2016-0042

19. Ruhi, Umar. (2014). Social Media Analytics as a Business Intelligence Practice: Current Landscape \& Future Prospects. Journal of Internet Social Networking \& Virtual Communities. 1-12. 10.5171/2014.920553.

20. Xiang, Z., Schwartz, Z. and Uysal, M. (2016). Market Intelligence: Social Media Analytics and Hotel Online Reviews. Tourism on the Verge, 281-295. https://doi.org/10.1007/978-3-319-44263-1_16 